\title{
Public Health Education in the United States: Then and Now
}

\author{
Linda Rosenstock, MD, MPH, ${ }^{1}$ \\ Karen Helsing, MHS, ${ }^{2}$ \\ Barbara K. Rimer, DrPH, MPH ${ }^{3}$
}

\begin{abstract}
It was against a background of no formal career path for public health officers that, in 1915 , the seminal Welch-Rose Report ${ }^{1}$ outlined a system of public health education for the United States. The first schools of public health soon followed, but growth was slow, with only 12 schools by 1960 . With organization and growing numbers, accreditation became an expectation. As the mission of public health has grown and achieved new urgency, schools have grown in number, depth and breadth. By mid-2011, there were 46 accredited schools of public health, with more in the pipeline. While each has a unique character, they also must possess certain core characteristics to be accredited. Over time, as schools developed, and concepts of public health expanded, so too did curricula and missions as well as types of people who were trained. In this review, we provide a brief summary of US public health education, with primary emphasis on professional public health schools. We also examine public health workforce needs and evaluate how education is evolving in the context of a growing maturity of the public health profession. We have not focused on programs (not schools) that offer public health degrees or on preventive medicine programs in schools of medicine, since schools of public health confer the majority of master's and doctoral degrees. In the future, there likely will be even more inter-professional education, new disciplinary perspectives and changes in teaching and learning to meet the needs of millennial students.
\end{abstract}

Key Words: Public health practice, education, public health professional methods, public health professional standards, financing, government, public health manpower

Recommended Citation: Rosenstock L, Helsing K, Rimer BK. Public Health Education in the United States: Then and Now. Public Health Reviews. 2011;33:3965 .

\footnotetext{
${ }^{1}$ University of California, Los Angeles School of Public Health. Los Angeles, CA.

${ }^{2}$ Institute of Medicine of the National Academies. Washington, DC.

${ }^{3}$ University of North Carolina at Chapel Hill Gillings School of Global Public Health. Chapel Hill, NC.
}

Corresponding Author Contact Information: Linda Rosenstock at lindarosenstock@ph.ucla. edu; University of California, Los Angeles School of Public Health. Los Angeles, CA, USA. 


\section{A HISTORY OF US PUBLIC HEALTH EDUCATION: THE PROFESSIONALIZATION OF PUBLIC HEALTH}

The history of the field of public health and the history of schools of public health (SPH) have been documented extensively ${ }^{2,3}$ and critiqued..$^{4-6}$ These histories developed in parallel, fueled initially by the need for sanitary engineers at a time when threats to health were largely from acute diseases, often the result of poor quality of water and sanitation. Epidemics and their consequences drove a demand for people trained in biology and outbreak management. Initially, those getting advanced training in public health were mostly people with medical backgrounds.

For much of the 19th century, there was no concept of organized public health. ${ }^{7}$ In the 1860 's, communities began to organize public health activities locally. The American Public Health Association (APHA) was formed in 1872, partly in response to increasing urbanization of the United States, and the growth of mechanization and factories, with their attendant health and safety risks. Infectious diseases, like tuberculosis, were rampant and spread quickly in the absence of good sanitation practices.

The first independent SPH in the US were funded privately, mostly by the Rockefeller philanthropies, which in the early 20th century had helped to define a public health profession. ${ }^{2,6}$ In 1915, the Rockefeller Foundation published a report by William Welch and Wickliffe Rose ${ }^{1}$ that outlined a system of public health education in the US, initially targeted at control of infectious diseases - a system that was university-based, research intensive and independent of medical schools. The Welch-Rose report was, in many ways, the parallel of the Flexner Report ${ }^{8}$ that had proposed a systematic approach to medical education in the wake of concerns about proliferating numbers of medical schools of dubious quality. Frenk et al. characterized this period in the history of public health as science-based. ${ }^{9}$ The WelchRose report was as revolutionary to public health schools as the Flexner Report was for medical schools.

The first US school of public health was Johns Hopkins School of Hygiene and Public Health, begun in $1916 .^{7}$ By 1936, there were ten SPH. Some but not all began in medical schools before becoming independent. Education "tended to be practically oriented" with considerable emphasis on public health administration, health education, public health nursing, vital statistics, diarrheal disease control and community health services and field programs. A 1938 evaluation, in the wake of the Great Depression, concluded that public health needs were greater than the number of trained personnel. ${ }^{2,3}$ Federal dollars were provided to several schools to create short courses to train health professionals in the field. Over the next several 
decades, tensions between the evolving fields of medicine and public health continued to be reflected in discussions about the future of public health.

By the 1950's, growth in the number of SPH had stalled (there were only 12 by 1960), and economic challenges of schools were large, dominated by inadequate funding to pay faculty salaries, obtain necessary facilities and purchase needed equipment. Schools increasingly turned to the National Institutes of Health $(\mathrm{NIH})$ for research funding. ${ }^{10}$ There was growing interest in building departments of preventive and community medicine within medical schools - many of these would prove forerunners of subsequent independent $\mathrm{SPH}$, but that future was uncertain and unplanned at the time.

The first major government investment in public health education came in 1960 with the Hill-Rhodes bill which provided funds for training and project grants for public health. This was the beginning of a period of renewed interest in public health as applications to SPH increased. ${ }^{7}$ Schools began to thrive, with growth from 12 SPH in 1960 to 20 in 1975. Concomitant with the growth in independent public health schools were important changes in the numbers and composition of formally trained public health professionals. During the 1960's teaching methods changed, with greater attention to problem-based learning, especially in medical schools. ${ }^{9}$

Support for public health professional education has been inconsistent over the decades, with a marked erosion of federal funding, beginning in the 1980's. This trend only reversed in the last few years but is again at risk in the wake of a serious recession. State government support also has been variable but significant; 34 of the current 46 schools are public institutions, with different levels of state assistance. Most schools with state funding have seen that support eroded over the last few years, some very significantly. A recent article in the Chronicle of Higher Education provided data about declines in state support for public universities. The average state cut was 0.7 percent, with at least four state cuts exceeding 11 percent. $^{11}$

\section{ROLES OF SPH}

Today, SPH train public health professionals at multiple levels, provide services to their local communities and beyond, and conduct research to prevent disease, disability and avoidable mortality at the individual, community and societal levels. Schools also translate research into evidence-based policies and practices in communities, clinical care settings and governments, non-governmental organizations (NGOs) and private organizations. Research in SPH ranges from basic laboratory research (e.g., 
to explain molecular signatures for particular viruses, cancers and other diseases) to applied research in communities as well as policy research. In fact, it is this continuum from basic research to translation of research into practice and policies that makes SPH especially relevant and skilled in solving problems. Public health researchers often collaborate with faculty in schools of medicine, pharmacy, dentistry, nursing, and others. They conduct bench and clinical research as well as communication research, comparative effectiveness studies, clinical effectiveness research and translational research, frequently with community-based research components. These varied roles reflect, in part, the fact that public health is not just a profession, ${ }^{10}$ but also a professional culture and commitment. ${ }^{12}$

SPH educate undergraduate, master's, doctoral, postdoctoral, and certificate students. Schools also provide continuing education to public health professionals within and beyond their geographic reach. The US Centers for Disease Control and Prevention (CDC) funds training centers within SPH charged with developing leadership skills among certain groups of health professionals (e.g., those from underserved groups). Similarly, the CDC has funded preparedness centers that focus on training particular kinds of professionals within assigned geographic regions. ${ }^{13,14}$ This training and related concepts enabled schools to provide direct responses to training needs of first responders and health department personnel, in response to the events following September 11, 2001 and outbreaks such as severe acute respiratory syndrome (SARS) and influenza A (H1N1). Since September 11, 2001, public health students and many practitioners are trained to understand concepts and language of biosurveillance, health risk communication, and the critical roles government agencies and nongovernment partners play in responding to public health emergencies. ${ }^{14}$

The landmark 1988 Institute of Medicine (IOM) report, The Future of Public Health, criticized SPH for being overly research intensive and disconnected from practice. ${ }^{4}$ In response, many schools made administrative and policy changes that institutionalized the means by which practice communities can access academic public health expertise and also increased opportunities for academicians to connect with communities. Despite some successes in addressing acknowledged deficiencies in practice, there still are many challenges to create permeable boundaries between academic public health and practice. For example, the need to demonstrate publication productivity may cause many younger faculty members to choose professional focus areas that have quicker timelines to publication than those required to build relationships and consensus with practice communities. Some schools have modified their appointments and 
promotion guidelines to reflect the importance of practice, but this varies from school to school.

Within SPH, students pursue their education with an extraordinarily interdisciplinary range of faculty, including biomedical scientists, medical care professionals, behavioral and social scientists (e.g., economics, sociology, politics), epidemiologists, biostatisticians, information scientists, lawyers, health service researchers and health educators, among others. As a result, SPH are well-positioned to be university leaders in collaborations with other schools, organizations and within the communities they serve. Increasingly, there are collaborations with schools of journalism, social work, and regional and city planning. This reflects, in part, recognition of the complexity of health and healthcare and the forces that influence them.

\section{ACCREDITATION AND CREDENTIALING}

The Association of Schools of Public Health (ASPH) was founded in 1941 by a group of seven SPH concerned about the growth of public health education programs. ${ }^{6}$ ASPH worked closely with APHA to develop standards and definitions for SPH. From 1945 to 1973, APHA conducted accreditation of graduate professional education in public health, at first centered almost exclusively in SPH, but later including other college and university settings.

In 1974, the independent Council on Education for Public Health $(\mathrm{CEPH}){ }^{15}$ was established by APHA and ASPH. Responsibility for evaluation of SPH was transferred to CEPH, which initially limited its focus to school accreditation. In the late 1970s, CEPH responded to requests from practitioners and educators to undertake accreditation of community health/ preventive medicine programs and to a request from APHA to assume additional responsibility for community health education programs. In 2005, these separate programmatic categories were combined into a single category of public health programs. CEPH is the accrediting body for $\mathrm{SPH}$, but other organizations accredit particular programs within SPH. These include The Commission on Accreditation for Dietetics Education (CADE) and the Commission on Accreditation of Health Management Education (CAHME).

ASPH started as an association "representing university faculties concerned with graduate education of professional personnel for service in public health; to promote and improve education and training of such personnel, and to do such other things as may improve the supply of trained personnel for all phases of public health activity." 16 Over time, ASPH became the national organization whose members are CEPH-accredited 
$\mathrm{SPH}$, not just in the US but internationally with inclusion of an accredited school in Mexico and an associate member school in France, which is in the process of accreditation. ASPH membership includes all CEPHaccredited member schools, 46 in 2011 (Figure 1), ${ }^{16,17}$ which together, graduate over 8,000 students each year.

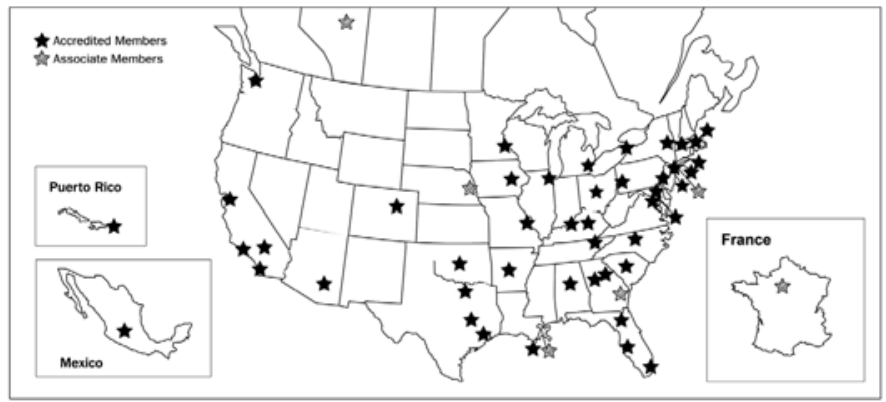

Fig. 1. Map of ASPH Accredited and Associate Members. This map of ASPH membership is from January 2011. ASPH represents the 46 CEPH-accredited SPH and the six associate members that intend to become fully accredited SPH through a formal review process administered by $\mathrm{CEPH}$.

Source: ASPH.org, Washington, DC; c2010 [member schools map]. ${ }^{17}$ Available from: http://www. asph.org/UserFiles/ASPH_map.pdf (Accessed 5 January, 2011).

Growth of schools and students in the most recent period has been dramatic (Figure 2). ${ }^{17}$ Additionally, six associate member schools are scheduled to become fully accredited SPH within the next two years, and others have indicated intent to become fully accredited. ${ }^{15,16}$ Growth of schools is expected to continue as states and private institutions recognize their value, and student interest grows.

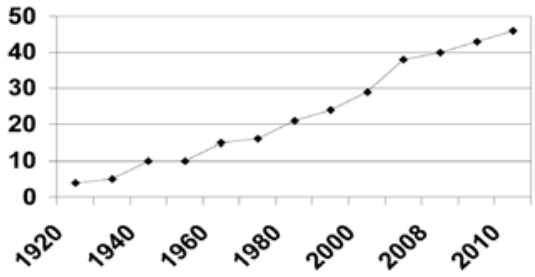

Fig. 2. Accredited SPH By Decade. This graph was compiled by ASPH Annual Data Reports. The rise in schools has grown steadily and rapidly in recent years.

Source: ASPH.org, Washington, DC; c2010 [ASPH annual data reports 1995-2009]. ${ }^{20}$ Available from: http://www.asph.org/ (Accessed 5 January, 2011). 
CEPH accredits about 75 public health programs in a variety of kinds of institutions, e.g., MPH programs in medical schools. Some programs are not CEPH-accredited. Estimates gathered from 2007 (Association for Prevention Teaching and Research; unpublished survey) indicate that less than 1,300 graduates/year come from CEPH-accredited programs. ${ }^{15}$ The number of graduates from unaccredited schools and programs is unknown. Several large, for-profit, online universities also offer public health programs and degrees. There is considerable concern about the growth and quality of these programs.

In an effort to establish public health as a recognized, certified profession, ASPH, APHA, the Association for Prevention Teaching and Research, the Association of State and Territorial Health Officials and the National Association of County and City Health Officials established the National Board of Public Health Examiners (NBPHE) in September 2005. NBPHE's purpose is to "ensure that students and graduates from schools and programs of public health accredited by CEPH have mastered the knowledge and skills relevant to contemporary public health." NBPHE is an active, independent organization that develops, administers and evaluates a voluntary certification exam once every year. ${ }^{18}$ Graduates of CEPHaccredited schools and programs are eligible to take the exam. As of this writing, the number of examinees each year is small (about 1,000) but growing. It is not known what the ultimate effect of the exam will be on job availability, selection, salaries or on the quality of the public health workforce.

\section{ACCREDITATION STANDARDS}

CEPH's focus is improvement of health through assurance of professional personnel who can identify, prevent and solve community health problems. ${ }^{15}$ The Council has several objectives, including to:

- Promote quality in public health education through a continuing process of self-evaluation by schools and programs that seek accreditation.

- Assure the public that institutions offering graduate instruction in public health have been evaluated and judged to meet standards essential for the conduct of such educational programs.

- Encourage-through periodic review, consultation, research, publications, and other means-improvements in the quality of education for public health.

To achieve this mission, CEPH reviews SPH resources, structure and programs through its established criteria, which are updated periodically. Accredited SPH must offer coursework in at least the five core areas of 
knowledge basic to public health: biostatistics; epidemiology; environmental health sciences; health services administration; and social and behavioral sciences. ${ }^{15}$ The core, broad knowledge areas form the basis of how schools structure curricula. However, schools are not limited to these disciplinary areas. Some schools have added departments of genetics, maternal and child health, nutrition and other areas. Nothing precludes expansion of the five core areas, but all students must get sufficient exposure to core public health disciplines (Table 1). ${ }^{15}$

Over the last several years, ASPH has developed competencies in a number of areas, such as undergraduate education and master of public health programs, and identified cross-cutting areas, such as cultural competence, public health biology and health informatics which augment the disciplinary focus of the core areas. Review of competencies shows the richness of subject matter area included under disciplinary areas, such as epidemiology. Across schools, it is expected that students gain skills in a variety of areas and also emerge with understanding about the multiple determinants of health, using the kind of social ecologic model identified in the IOM report, Who Will Keep the Public Healthy?6

The accreditation process is based on peer review, in which a site visit team visits each school and evaluates their self-study and the processes behind it. According to the CEPH website ${ }^{15}$, site visitors must:

- Be a senior academician (e.g., dean, associate dean, department chair or senior faculty member); or

- A senior public health practitioner (i.e., primarily employed by a public health department, non-profit organization, healthcare organization, etc. with preferably at least 10 years of experience in public health); and

- Have at least a master's degree (practitioners) or a doctoral degree (academicians); and

- Possess strong writing, communication and analytical skills.

$\mathrm{CEPH}$ is responsible for selecting site visit teams, chairs and assuring that guidelines are followed throughout the accreditation process for each school (Table 1). ${ }^{15}$

In 2005, CEPH amended and strengthened accreditation criteria for schools. SPH now are required to have at least five full-time faculty members for each of the five core areas of study (minimum of 25 faculty members) and must offer at least three doctoral degrees in three distinct programmatic areas. Again, they are not restricted to this minimum, and most mature schools have many more programs. Some also offer joint degrees with schools of social work, medicine, dentistry, nursing, city and regional planning, law, business, information and library sciences and other areas. Accreditation requirements are a floor and not a ceiling. 


\section{Table 1}

Core Accreditation Areas, CEPH Criteria 2005

\begin{tabular}{c|l}
\hline \multicolumn{2}{c}{ Areas of Knowledge Basic to Public Health } \\
\hline Biostatistics & $\begin{array}{l}\text { - Collection, storage, retrieval, analysis and interpretation of } \\
\text { health data. } \\
\text { - Design and analysis of health-related surveys and experiments. } \\
\text { - Concepts and practice of statistical data analysis. }\end{array}$ \\
\hline Epidemiology & $\begin{array}{l}\text { - Distributions and determinants of disease, disabilities and } \\
\text { death in human populations. }\end{array}$ \\
\hline Environmental Health \\
Sciences & $\begin{array}{l}\text { - Tharacteristics and dynamics of human populations. } \\
\text { Environmental factors including biological, physical and } \\
\text { chemical factors that affect the health of a community. }\end{array}$ \\
\hline $\begin{array}{c}\text { Health Services } \\
\text { Administration }\end{array}$ & $\begin{array}{l}\text { - Planning, organization, administration, management, } \\
\text { evaluation and policy analysis of health and public health } \\
\text { programs. }\end{array}$ \\
\hline $\begin{array}{c}\text { Social and Behavioral } \\
\text { Sciences }\end{array}$ & $\begin{array}{l}\text { - Concepts and methods of social and behavioral sciences } \\
\text { relevant to the identification and solution of public health } \\
\text { problems. }\end{array}$ \\
\hline
\end{tabular}

Source: CEPH.org, Washington, DC; c2010 [CEPH accreditation criteria, 2005]. Available from: http://www.ceph.org/pdf/SPH-Criteria.pdf (Accessed 13 June, 2011).

Schools must be independent, with status similar to other professional schools at their universities. That aside, the perceived value of SPH undoubtedly varies across universities and is likely to be affected by a school's rankings, success in obtaining grants and contracts and other issues.

Criteria for programs are similar to those for schools, with some differences. Each degree program and area of specialization must have clearly stated competencies that guide development of educational programs. These define what a successful learner should know and be able to do upon completion of a particular program or course of study. ASPH developed master's degree core competencies in 2006 to serve as a resource and guide and continues to develop competencies in several other priority areas, such as preparedness.

Accreditation has both advantages and disadvantages. From the perspective of students and the field, accreditation assures a minimum level of quality in relation to established criteria. Specifying core disciplines that must be represented and taught, identifying core competencies and clearly specifying relationships between goals, learning objectives and student 
outcomes is a strength of the process. But such a process also carries threats to innovation if criteria are interpreted too narrowly and do not permit new developments in format, methods and content of training programs. There also is more emphasis on teaching and service aspects of schools and less on research which, for research universities, is an important part of the mission. In addition, costs of accreditation, both direct and indirect, have grown as the complexity of the process has grown. Lengthening the time period between reviews might be appropriate in view of this.

\section{PROFILE OF GRADUATE TRAINEES IN SPH}

Fifty years ago, the profile of a public health student was a white physician or nurse who pursued an MPH in order to practice at a health department or other similar setting. Today, about eight percent of public health students have medical degrees. ${ }^{19}$ Current public health students are younger, with less work experience, and more varied in the academic disciplines and the perspectives they bring to the profession. They also are more diverse in terms of ethnicity, race, age, socioeconomic backgrounds and culture and related characteristics. ${ }^{20,21}$

Students' and trainees' characteristics vary as much as diversity of the schools themselves. In 2009, over 25,000 students were enrolled in accredited SPH (Table 2); about one third of students were part-time, and many were trained in online programs with limited in-person classroom contact hours (distance education offered at 19 schools). In 2009, females represented 72 percent of graduates. Minorities (including Asians) received 32 percent of graduate degrees awarded to US students. Sixty percent of graduates received MPH degrees. Doctoral degree recipients were dominated by PhDs, about 15-fold more often than Doctor of Public Health graduates. International students, despite small dips in enrollment in recent years, continue to grow and now constitute 17 percent of graduates. In 2009 , across all accredited SPH, there were over 4,700 faculty members. ${ }^{20}$

Overall, program areas with highest concentrations of graduates are health services administration (20\%), epidemiology (17\%) and health education/behavioral sciences (12\%). "Other" program areas included 12 percent of graduates, despite efforts to categorize degree classifications into one of the ten categories in ASPH's Annual Survey.$^{20}$ This may reflect diversity of offerings, as well as efforts to adapt to new priority areas and other emerging areas of focus, such as health equity, health systems modeling, public health preparedness, health implications of climate change, and chronic disease prevention. 
Table 2

Accredited School of Public Health, Graduate Student Size in 2009 and Founding Year

\begin{tabular}{|c|c|c|}
\hline Accredited School of Public Health & $\begin{array}{l}\text { Total Number of } \\
\text { Graduate Students } \\
\text { in } 2009\end{array}$ & $\begin{array}{l}\text { Year of First } \\
\text { CEPH } \\
\text { Accreditation }\end{array}$ \\
\hline Boston University & 639 & 1981 \\
\hline Columbia University & 1081 & 1946 \\
\hline Drexel University & 327 & 2004 \\
\hline East Tennessee State University & 101 & 2000 \\
\hline Emory University & 986 & 1978 \\
\hline Florida International University & 851 & 1993 \\
\hline George Washington University & 878 & 1990 \\
\hline Harvard University & 1067 & 1946 \\
\hline Instituto Nacional de Salud Publica & 502 & 2006 \\
\hline Johns Hopkins University & 1717 & 1946 \\
\hline Loma Linda University & 495 & 1967 \\
\hline Ohio State University & 341 & 1985 \\
\hline Saint Louis University & 353 & 1983 \\
\hline San Diego State University & 380 & 1982 \\
\hline Texas A\&M Health Science Center & 274 & 2001 \\
\hline Tulane University & 998 & 1947 \\
\hline $\begin{array}{l}\text { University of Medicine and Dentistry } \\
\text { New Jersey Rutgers, The State University of } \\
\text { New Jersey and the New Jersey Institute of } \\
\text { Technology }\end{array}$ & 339 & 1986 \\
\hline University at Albany - SUNY & 324 & 1993 \\
\hline University at Buffalo - SUNY & 419 & 2009 \\
\hline University of Alabama at Birmingham & 413 & 1978 \\
\hline University of Arizona & 226 & 1994 \\
\hline University of Arkansas for Medical Sciences & 109 & 2004 \\
\hline University of California, Berkeley & 503 & 1946 \\
\hline University of California, Los Angeles & 659 & 1960 \\
\hline University of Florida & 905 & 2009 \\
\hline University of Georgia & 179 & 2009 \\
\hline
\end{tabular}




\begin{tabular}{|c|c|c|}
\hline Accredited School of Public Health & $\begin{array}{c}\text { Total Number of } \\
\text { Graduate Students } \\
\text { in } 2009\end{array}$ & $\begin{array}{c}\text { Year of First } \\
\text { CEPH } \\
\text { Accreditation }\end{array}$ \\
\hline University of Illinois in Chicago & 594 & 1972 \\
\hline University of Iowa & 368 & 2000 \\
\hline University of Kentucky & 212 & 2005 \\
\hline University of Louisville & 157 & 2007 \\
\hline University of Massachusetts & 463 & 1970 \\
\hline University of Michigan & 852 & 1946 \\
\hline University of Minnesota & 1189 & 1946 \\
\hline University of North Carolina, Chapel Hill & 1376 & 1946 \\
\hline $\begin{array}{l}\text { University of North Texas Health Science } \\
\text { Center }\end{array}$ & 255 & 1999 \\
\hline University of Oklahoma & 239 & 1967 \\
\hline University of Pittsburgh & 590 & 1950 \\
\hline University of Puerto Rico & 494 & 1956 \\
\hline University of South Carolina & 655 & 1977 \\
\hline University of South Florida & 795 & 1987 \\
\hline $\begin{array}{l}\text { University of Texas Health Science Center at } \\
\text { Houston }\end{array}$ & 850 & 1969 \\
\hline University of Washington & 812 & 1970 \\
\hline Yale University & 275 & 1946 \\
\hline TOTAL (43 Schools) & 25241 & \\
\hline
\end{tabular}

Notes: This table lists each accredited school of public health and the size of their graduate student body in 2009. Data on their founding year of accreditation is also included.

Source: ASPH.org. Washington, DC; c2010 [ASPH annual data report 2009]. ${ }^{20}$ Available from: http://www.asph.org/ (Accessed 30 March, 2011).

Graduates from public health accredited schools and programs conduct research and teach in universities, international bodies and nonprofit organizations, manage healthcare and health insurance systems, work in the private sector and for foundations, are public health leaders in state, local and federal health agencies, and work globally and locally in many different roles. 


\section{PUBLIC HEALTH EDUCATION FOR UNDERGRADUATES, HEALTH PROFESSIONALS AND OTHERS}

In the US, academic public health continues to grow in size and stature. The scope of public health education is expanding to new collaborations among health professions and other professional degree programs and includes college and even high school students. Broadening public health education as a core body of knowledge for students, not just in other health professional schools but well beyond, was augured by the IOM's 2003 report, Who Will Keep the Public Healthy? ${ }^{6}$ Specifically, the report called for a dramatic upsurge in master's level training in public health for medical professionals, citing the need to train as many as half of all medical school students at this level.

Inter-professional education extends far beyond more traditional medicine and public health training. For public health, it is seen when multiple professions' disciplines collaborate to advance the knowledge and skills of professionals and students. Public health schools have a long history of collaboration with other schools and colleges within their own universities. These include formal dual degree opportunities. Some of the most common joint degrees include MPH/MD degrees, but also degrees joint with law (MPH/JD), dentistry (MPH/DDS), social work (MPH/MSW), nursing (MPH/MSN), business (MPH/MBA) and veterinary medicine (MPH/DVM). Several schools offer dual degree training with schools of communications, journalism, information and library science, public policy, city and regional planning, education and international affairs. These combinations allow students to integrate curricula towards their particular interests. There is no conceptual limit to potential joint and dual degree programs; they are likely to increase in the coming years.

For many years, a small number of schools offered undergraduate study of public health including public health majors. Recently, public health has emerged in a broad spectrum of undergraduate programs amidst growing interest in public health. In 2008, the American Association of Colleges and Universities surveyed their membership and found that 167 institutions offered undergraduate majors, minors or concentrations in public health. ${ }^{22}$ Universities with SPH clearly dominate the playing field, with 15 schools offering public health as a major area of concentration, and 14 offering a minor concentration, accounting for nearly 3,000 undergraduate students in 2008. A recent front page Washington Post story captured this interest, in an article entitled "For a Global Generation, Public Health is a Hot Field." 23 
Public health as a field has an increasingly wide appeal for students concerned with what the $21^{\text {st }}$ century holds for the world's population, and some potential applicants would like to be able to enter the field with less time in school. Additionally, there is also increased attention to opportunities at the community college level for public health education. ${ }^{24}$ Applicants' interest in SPH is growing at a remarkable rate, eclipsing other health professional fields, such as medicine. There was a 75 percent growth in the number of applicants between 1998 and 2008, from about 20,000 to 35,000/ year. $^{20}$

\section{SOURCES OF SUPPORT FOR SPH}

Despite annual healthcare costs in the neighborhood of \$2 trillion USD/ year, the US ranks $46^{\text {th }}$ in life expectancy and $42^{\text {nd }}$ in infant mortality among the world's 192 nations. ${ }^{19}$ The US invests less than two percent of each heathcare dollar on prevention while spending 75 percent of that dollar treating preventable diseases. ${ }^{25}$ Such an imbalance defies peer-reviewed findings that show prevention activities in most instances are far more costeffective in improving health than medical treatment. ${ }^{25,26}$

Unlike medical schools, SPH do not receive core federal funding for education [beyond a small pool of students], such as is received through Medicare funding for medical residents or core federal funding for research and service/care available through the Veterans Administration for faculty effort.

While the NIH bench science model drives much of the highly valued research at SPH, progress has been made in garnering NIH and foundation support for applied research in epidemiology, behavioral sciences, health policy, and environmental health. Limited fiscal resources, however, often make it difficult to mobilize and sustain research articulated by the practice sector and communities of need.

Funding for SPH comes from a variety of sources, which include:

- Tuition and federal sources: Health Resources and Services Administration (HRSA), CDC and NIH funding of students;

- Research supported by federal, state, city and not-for-profit organizations ( $\$ 764$ million in 2009), and

- Foundation, corporate and philanthropic support.

- State and city universities and colleges often receive support from the relevant governmental level. The amount of this support varies, and has in general been significantly declining in recent years. For example at UC Berkeley and UCLA, core support has eroded to about 10 percent. 
Funding at SPH ebbs and flows depending on current governmental priorities. As McGinnis and Foege observed, "one of the most difficult challenges is that the urgent does not crowd out the important. In health, this challenge is especially difficult, because urgent matters can be so riveting..."27 Examples of interventions with known major impacts on individual health include tobacco control and injury prevention activities. However, as Colgrove et al. stated, "the current funding system for SPH is piecemeal and largely reactive and constrains the ability of SPH to meet essential societal needs. We argue that the federal government should invest significant and sustained financial support for this work through a dedicated funding stream." ${ }^{28}$ This would be a milestone for a field that lacks support to carry out its essential functions.

\section{PUBLIC-PRIVATE PARTNERSHIPS IN PUBLIC HEALTH EDUCATION}

Several programs at SPH contribute to the nation's health through provision of effective, up-to-date public health training to public health workers via a network of regional centers. To successfully carry out their charge, these centers have formed formal partnerships, particularly with local and state health agencies.

In late 2010, HRSA funded 27 Public Health Training Centers (PHTC), 23 of which are located at SPH, nearly doubling the previous network of 14 training centers. PHTCs aim to develop the existing public health workforce as a foundation for improving the infrastructure of the public health system. PHTCs are based on collaborations with health departments and foster close advisory roles for academia and practice partners in their geographic areas.

CDC-supported Centers for Public Health Preparedness (CPHP) which began in 2000 and funded schools to prepare frontline public health workers to respond to bioterrorism and infectious disease outbreaks. ${ }^{13}$ In 2010, these centers were redesigned, and new Preparedness and Emergency Response Learning Centers (PERLC) were funded at 14 schools. These centers support workforce development needs by offering assistance to their state, local and tribal public health partners and are developing consistent curricula using public health workforce competencies.

In 2008, CDC funded nine schools to establish Preparedness and Emergency Response Research Centers (PERRCs). Centers connect public health researchers with scientists involved in business, engineering, legal, and social sciences and conduct research that will evaluate the structure, 
capabilities, and performance of public health systems for preparedness and emergency response activities.

The CDC Prevention Research Centers (PRC) Program ${ }^{29}$ funds 37 prevention centers, the majority of which are housed in SPH. The PRC Program is an effective model for applied population-based prevention research. Community and research partners collaborate to develop programming and identify successful aspects of research projects that can be disseminated to other communities. PRCs play a leading role in translating bench and clinical research findings into practice in complex and diverse community settings. This kind of research, which adapts, refines, and demonstrates the effectiveness of community interventions, is contributing to understanding mechanisms for improving the health of populations. PRCs are integrally related to public health education, not just through interactions with community public health professionals but also through opportunities for involvement of students.

Examples of other research and training centers in SPH include:

- Education and Research Centers (NIOSH), which conduct research and training and make recommendations for the prevention of work-related illnesses and injuries;

- Centers of Excellence in Health Statistics (NCHS), which improve data collection systems to help develop and evaluate prevention programs;

- Injury Prevention Centers (NCIPC), which fund and monitor research in three phases of injury control: prevention, acute care, and rehabilitation;

- Centers for Genomics and Public Health (NCEH), which study all elements of our human genome and how they relate to human health and disease;

- Public Health Research and Education Centers (PHRECs) within the Veteran's Administration, which conduct research, education and outreach on health promotion and disease prevention activities for veterans; and,

- Centers of Excellence in Environmental Health (NCEH), which partner with state and local health departments, to develop state-of-the-art environmental health programs based on the 10 Essential Public Health Services.

In addition to these examples, there are many other centers and institutes within SPH. 


\section{ASSESSING PUBLIC HEALTH WORKFORCE NEEDS}

Public health professionals have been forced over an extended period of time to do more with fewer people, a problem greatly exacerbated by the recent global recession. "Given the increasing complexity of public health science, meeting these challenges means training many more specialists in the many sub-disciplines of public health. As well, the availability and capacity of a global public health workforce needs to be significantly expanded." 21

Although for some time, there has been widespread recognition that the US has a shortage of well-trained public health professionals, no quantitative estimates of projected needs had been taken prior to 2007. ${ }^{31}$ At that time, a taskforce of the ASPH set about quantifying public health workforce needs projected for 2020. ${ }^{6,30,31}$ We summarize below the findings and implications of the workforce report and related subsequent efforts. ${ }^{21}$

As shown in Table 3, "in 2000, there were 50,000 fewer public health employees than in $1980 . .^{32,33}$ The workforce ratio in $1980-220$ public health workers for every 100,000 US residents-although a likely underestimate of need, was used as a benchmark. ${ }^{21}$ Given population increases, a total of 600,000 (vs. the 450,000 available) would have been necessary in 2000 to maintain the workforce ratio that existed two decades earlier. In 2020 , a public health workforce of more than 700,000 would be needed to achieve the 220:100,000 ratio. That creates a need for some 250,000 more workers than are available today." ${ }^{21}$

Table 3

Public Health Workforce to US Population Ratios

\begin{tabular}{c|c|c|c}
\hline Year & US Population & $\begin{array}{c}\text { Ratio of the Public Health } \\
\text { Workforce to US Population }{ }^{21}\end{array}$ & $\begin{array}{c}\text { Public Health } \\
\text { Workforce }\end{array}$ \\
\hline 1980 & $226,542,199$ & 220 per 100,000 & 500,00032 \\
\hline 2000 & $281,421,906$ & 159 per 100,000 & 448,25433 \\
\hline $2020^{*}$ & $320,000,000$ & 220 per 100,000 & 700,000 \\
\hline
\end{tabular}

* Projected Need

Source: Association of Schools of Public Health (ASPH). ASPH policy brief-Confronting the public health workforce crisis: executive summary. Washington, DC: The Association; 2008 Dec. 9. ${ }^{21}$ Available from: http://www.asph.org/UserFiles/WorkforceShortage2008Final.pdf (Accessed 5 January, 2011). . $11,32-34^{2}$ 
Even that number is undoubtedly conservative, since public health departments across the US absorbed substantial personnel cuts during the recession of 2008-2010. Extrapolation of these data to projected shortages by state is demonstrated in Figure 3. These estimates also do not take into account the large potential retirement effects of an aging worker cohort. Although some retirements may be postponed due to the economic recession, by 2012 , more than 110,000 US public health workers in government-24 percent of an estimated 450,000-person workforce-will be eligible to retire. In addition, the estimates are supply-based and do not attempt to quantify need or demand or the serious issue of geographic distribution and discipline-specific projects (e.g., laboratory workers vs. epidemiologists).

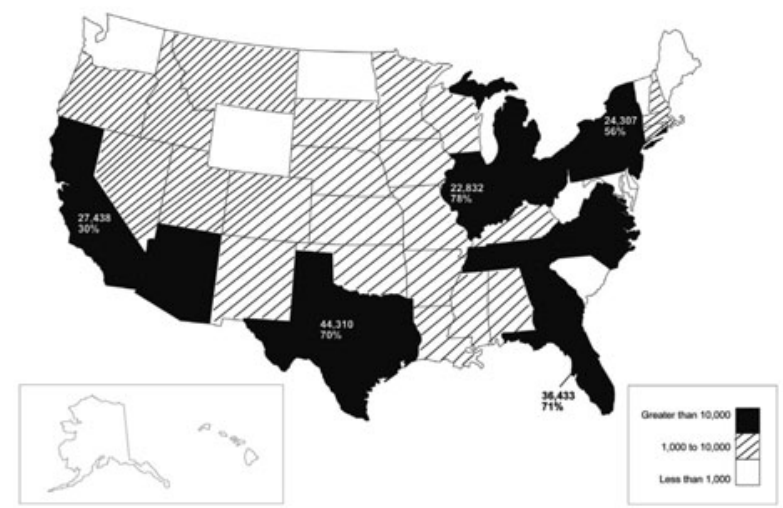

Fig. 3. The Projected Public Health Workforce Shortage in 2020, US by State. This map illustrates projected shortages of state public health workers from data compiled in 1998 by the ASPH Taskforce on the Public Health Workforce. Data was based on state estimates provided by the Association of State and Territorial Health Officials.

Source: Association of Schools of Public Health (ASPH). ASPH policy brief-Confronting the public health workforce crisis: executive summary. Washington, DC: The Association; 2008 Dec. 9. ${ }^{21}$ Available from: http://www.asph.org/UserFiles/WorkforceShortage2008Final.pdf (Accessed 5 January, 2011).

Several other organizations (e.g., APHA ${ }^{35}$, Trust for America's Health, ${ }^{36}$ Association of Academic Health Centers (AAHC) ${ }^{37}$ ) and efforts have addressed specific disciplines. For example, the American Association of Medical Colleges (AAMC) has reported a shortage of 10,000 public health physicians, recommending a doubling of public health physicians currently in practice. ${ }^{38}$ 
Moreover, there are demonstrated racial and ethnic disparities and significant geographic gaps in the public health workforce as the Sullivan Commission on Diversity in the Healthcare Workforce concluded. ${ }^{39}$

"Today's physicians, nurses, and dentists have too little resemblance to the diverse populations they serve, leaving many Americans feeling excluded by a system that seems distant and uncaring. The fact that the nation's health professions have not kept pace with changing demographics may be an even greater cause of disparities in health access and outcomes than the persistent lack of health insurance for tens of millions of Americans."

Sullivan Commission on Diversity in the Healthcare Workforce. ${ }^{39}$

Public health workforce shortages are even more critical in much of the developing world. For example, sub-Saharan Africa has 11 percent of the world's population and 24 percent of the global burden of disease-yet it commands less than one percent of the world's health expenditures. ${ }^{40}$ The World Health Organization has said there is a "major mismatch" between population needs and the available public health workforce in terms of overall numbers, relevant training, practical competencies and sufficient diversity to serve all individuals and communities. ${ }^{39,41}$

\section{GLOBAL HEALTH EDUCATION IS INTEGRAL TO PUBLIC HEALTH}

Events and population health changes of the last few decades, have shown that countries do not exist in isolation and are increasingly interdependent. ${ }^{9,42,43}$ Health professionals move from one country to another in a permeable manner. Similarly, health conditions know no borders. ${ }^{9.42}$ An epidemic that starts in the US, Africa or Thailand may become worldwide for non-communicable conditions as well as communicable diseases. Tobacco companies found global markets after they became stymied in the US. A similar phenomenon is occurring with regard to availability of processed foods and obesity. The Internet has made global communication instantaneous and accessible to more and more individuals regardless of country. Burgeoning funding for AIDS through the US President's Emergency Fund for AIDS Relief (PEPFAR) provided support for many public health researchers to conduct global research.

Older US SPH have undertaken global activities for many years, although in the past, the area was referred to as international health. In Dreaming of a Time,${ }^{44}$ Korstad described the global travels and sanitation 
consultation of faculty in Environmental Sciences and Engineering at the University of North Carolina in the 1950's and 1960's. In other departments, faculty members and students traveled around the world as they worked on health projects. Participation of Americans in leading roles in international health, such as outlined in the Preface to this edition by Donald Henderson, ${ }^{45}$ was not uncommon. However, except in a few schools with organized departments of international health (such as Harvard and Johns Hopkins), systematic attention to international/global health was inconsistent. Today, most SPH have global health activities; some have large, organized programs. For example, according to a survey of ASPH members (Spencer HC. Unpublished data. 2010):

- At least 19 schools offer concentrations in global health (sometimes these are certificates or minors) while others have globalized their curricula;

- Over half the schools have formal research or academic global health collaborations with other schools within their universities (such as medical schools, nursing, law);

- Nearly 80 percent of schools have formal education, research, practice and service activities in Asia, Africa and the Americas;

- Over half the schools have NIH funding for global health activities. Much of this came initially from the Fogarty Institute;

- Over half the schools have twinning relationships with countries in Asia, Africa and the Americas; and

- Most schools plan to increase their global health activities.

ASPH is leading an effort to develop global health competencies, and individual schools have been engaged in this effort as well. ${ }^{46}$ To many, global health and public health are indistinguishable. ${ }^{42}$ Both global health and public health share many characteristics, including an emphasis on population-level policies, as well as individual approaches to health promotion. The Commission on Education of Health Professionals for the $21^{\text {st }}$ Century ${ }^{9}$ said that "maintaining a comparative global perspective can enrich existing curricula, thereby reducing the demand for extra time and space." The current focus on global health, separate from international health, is broader and not solely about developing countries.

\section{FUTURE DIRECTIONS AND CONCLUSIONS}

The US is approaching 100 years of formalized public health professional education. Some features present at the outset remain today, notably, recognition of a distinct field that is science-based across a broad spectrum of activities, from the laboratory to bedside to communities, both 
domestically and globally. There continues to be some tension about the relationship between medicine and public health, with some holding to distinct boundaries, and others claiming the need for better integration. However, with broad research collaborations across schools and growing numbers of medical students receiving public health training, old dichotomies between medicine and public health are breaking down. Even the term has come under review, with an increasing number of cited references referring to population health as a better descriptor of the field conventionally known as public health.

Much has changed; with change has come evolution in the structure and functions of public health education. Globalization has spared little, and certainly not the health arena. As recognition of the importance of global health has grown, and with it, attendant economic resources, the area of global health - which an increasing number would define as synonymous with global public health - has caught on with great interest, capturing the increasing attention of the medical education and care communities as well. ${ }^{42,43}$ Public health schools and training programs have responded to the growing interest of students and have flourished as they couple this interest with longstanding activities of their own faculties.

Perhaps most dramatic over the past 100 years is growth in numbers of students and their diversity. This trend promises to continue despite economic challenges created by recession. Our field is exciting and better understood than it has been throughout most of its history. The importance of public health education should continue to grow, not only as its own distinct field but in the context of increasing interprofessional education, team-based learning and increasing opportunities to link research and education to didactic learning and practice, in the US and globally.

Over the last few decades, there has been greater attention paid to building the evidence base for public health, adapting a model that originally was built for medicine and operationalized in the US Preventive Services Task Force (USPSTF). The CDC's Task Force on Community Preventive Services is the US body charged with assessing evidence for public health interventions ${ }^{47,48}$ Focus on building the evidence base for public health is an important trend.

This review has not focused on changes in healthcare delivery and payment that accompany the Patient Protection and Affordable Care Act. ${ }^{48}$ Expansion of health insurance coverage for millions of Americans is accompanied by a number of central issues relevant to public health education, including a central emphasis on the importance of prevention and public health, with recognition of the importance of workforce 
development and funding. Moreover, there is a large role for SPH in conducting comparative effectiveness research to answer important questions about which public health and healthcare interventions are most effective in practice. ${ }^{49} \mathrm{We}$ look forward to major opportunities to improve and innovate in public health education as a result of the passage of this historic legislation.

As we enter a new decade, well-trained public health graduates are needed more than ever before. We face huge global threats, such as lack of safe water, emerging infections, wars, global income inequality, climate change, global obesity epidemic and changing demographic patterns associated with global aging. New technologies have potential to ameliorate some of the divide between rich and poor, developed and developing countries by providing access to information and tools to use information for improving the health of individuals and societies. As globalization makes the world smaller, public health graduates from the US and other countries are needed to strengthen health systems around the world. The complexity of these problems requires that students be trained, not in disciplinary silos but in interdisciplinary environments where they learn how to discover, find, synthesize and use information for health improvement.

The Commission on Health Professionals for a New Century, ${ }^{9}$ an ambitious agenda for health professional training in the new century concluded, "The next generation of learners needs the capacity to discriminate vast amounts of information and extract and synthesize knowledge that is necessary for clinical and population-based decision making." New skills, like data mining and visualization, will become increasingly important as we face terabytes of data that require sense making. Research synthesis and health informatics also are likely to be increasingly important. Some schools have begun to integrate teaching of the core disciplines, on the assumption that most students will work in interdisciplinary settings, and that the silo approach to disciplines is no longer appropriate. Over time, it is likely that there will be more integrated teaching and learning across disciplines, because the amount of content is growing at an enormous rate, beyond what can be absorbed into courses conducted in isolation. Inter-professional training should become more frequent, as well.

We look forward with great interest and enthusiasm to changes that are likely to come in SPH as our students increasingly demonstrate that they learn and communicate very differently than their predecessors. The millennial generation of students and teachers is expanding conventional 
teaching with their use of new media and their skills for information search and synthesis. ${ }^{50,51}$ We anticipate that, coupled with additional technological advances, these factors will drive significant changes in the way we educate future generations of public health professionals. For example, future classrooms are likely to offer global connections to facilitate hybrid learning, with students from different countries participating in discussions. Students increasingly view themselves as global citizens, and that bodes well for the future of public health. ${ }^{51}$

\section{Future Issues list:}

- Need for stable core funding for schools of public health.

- Changing patterns of teaching and learning for new generations of students.

- Integrating global and domestic missions of public health.

- Integrating academic and practice missions.

- Accommodating the tremendous knowledge explosion within the context of accreditation expectations.

- Dealing with new problems, (e.g., climate change), and new disciplinary areas, (e.g., neuroscience).

- Need for more inter-professional education among health sciences schools.

Key points:

- Accredited schools of public health have grown and continue to grow in number, depth and breadth.

- Despite growth of programs, there is widespread recognition that the US has a shortage of well-trained public health professionals.

- Accredited SPH train professionals at multiple levels, provide service to local and global communities, and conduct and translate research at the individual, community and societal levels.

- Despite many successes in addressing public health practice contributions in academia, there remain many challenges (e.g., most schools lack consistent funding mechanisms that are not research-oriented).

- With globalization and increased complexity involved in strengthening health systems around the world, today's students must be trained, not in disciplinary silos but in interdisciplinary environments.

Acronyms list:

APHA $=$ The American Public Health Association

ASPH $=$ The Association of Schools of Public Health

$\mathrm{CEPH}=$ The Council on Education for Public Health

NBPHE $=$ The National Board of Public Health Examiners

HRSA $=$ The Health Resources and Services Administration

PHTC $=$ Public Health Training Centers

$\mathrm{PRC}=$ Prevention Research Center

$\mathrm{SPH}=$ Schools of public health

Conflicts of Interest: None declared. 


\section{REFERENCES}

1. Welsh WH, Rose W. Institute of Hygiene: a report to the General Education Board of Rockefeller Foundation. New York: The Rockefeller Foundation; 1915. Available from URL: http://www.deltaomega.org/WelchRose.pdf (Accessed 5 January, 2011).

2. Fee E, Rosenkrantz B. Professional education for public health in the United States. In: Fee E, Acheson R, editors. History of Education in Public Health. New York: Oxford University Press;1991. pp. 230-71.

3. Terris M. Evolution of public health and preventive medicine in the United States. Am J Public Health. 1975;65:161-9.

4. Board on Health Promotion and Disease Prevention. The future of public health. Institute of Medicine of the National Academies. Washington, DC: National Academies Press; 1988. Available from URL: http://www.nap.edu/ nap-cgi/report.cgi?record_id=1091\&type=pdfxsum (Accessed 5 January, 2011).

5. Board on Health Promotion and Disease Prevention. The future of the public's health in the 21st century. Institute of Medicine of the National Academies. Washington, DC: National Academies Press; 2002. Available from URL: http://books.nap.edu/openbook.php?record_id=10548 (Accessed 5 January, 2011).

6. Gebbie KM, Rosenstock L, Hernandez L, editors. Board on Health Promotion and Disease Prevention. Who will keep the public healthy? Educating public health professionals for the 21 st century. Institute of Medicine of the National Academy of Sciences. Washington, DC: National Academies Press; 2003.

7. Fee E. Disease and discovery: A history of the Johns Hopkins School of Hygiene and Public Health, 1916-1939. Baltimore, MD and London: The Johns Hopkins University Press; 1987. Chapter 8.

8. Flexner A. Medical education in the United States and Canada: a report to the Carnegie Foundation for the Advancement of Teaching. New York, NY: Carnegie Foundation for the Advancement of Teaching; 1910.

9. Frenk J, Chen L, et al. Health professionals for a new century: transforming education to strengthen health systems in an interdependent world. Lancet. 2010;376:1923-58.

10. West MD, Gooch M, Raup, RM. Federal support of schools of public health. Public Health Rep. 1962;77:779-88.

11. The Chronicle of Higher Education. State support for higher education continues to fall. 24 January, 2001. Available from URL: http://chronicle.com/article/ Interactive-Map-State-Support/126032/ (Accessed 30 March, 2011).

12. Tulchinsky TH, Bickford MJ. Are schools of public health needed to address public health workforce development in Canada for the 21st century? Can J Public Health. 2006;97:248-50. 
13. Public Health Reports. Supplement 5: Public health preparedness. Public Health Rep. 2010;125:S5. Available from URL: http://www.publichealthreports.org/ archives/issuecontents.cfm? Volume=125\&Issue=11 (Accessed 24 June, 2011).

14. Baker EL, Lichtveld, MY, MacDonald PDM. Centers for public health preparedness program: from vision to reality. Public Health Rep. 2010;125: S4-7.

15. Council on Education for Public Health. CEPH: Washington, DC; 2010. Available from: http://www.ceph.org/ (Accessed 5 January, 2011).

16. Association of Schools of Public Health. ASPH: Association of Schools of Public Health. Washington, DC; 2010. Available from URL: http://asph.org/ (Accessed 5 January, 2011).

17. Association of Schools of Public Health. ASPH: Association of Schools of Public Health. Member schools map. Washington, DC; 2010. Available from URL: http://www.asph.org/UserFiles/ASPH_map.pdf (Accessed 5 January, 2011).

18. Publichealthexam.org. NBPHE: National Board of Public Health Examiners. Pittsburgh, PA; 2010. Available from: http://www.publichealthexam.org/ (Accessed 5 January, 2011).

19. Kennedy C, Baker T. Changing demographics of public health graduates: potential implications for the public health work force. Public Health Rep. 2005; 120:355-7.

20. Association of Schools of Public Health. ASPH annual data report 2009. Washington, DC; 2010. Available from URL: http://www.asph.org/UserFiles/ Data\%20Report\%202009.pdf (Accessed 5 January, 2011).

21. Association of Schools of Public Health (ASPH). ASPH policy brief-Confronting the public health workforce crisis: executive summary. Washington, DC: The Association; 2008. Available from URL: http://www.asph.org/UserFiles/ WorkforceShortage2008Final.pdf (Accessed 5 January, 2011).

22. Hovland K, Kirkwood BA, Ward C, Osterweis M, Silver GB. Liberal education and public health: surveying the landscape. Peer Review (AAC\&U). 2009; 11:5-8.

23. Brown D. For a global generation, public health is a hot field. The Washington Post. 19 September, 2008; Sect A:1.

24. Honoré PA, Graham GN, Garcia J, Morris W. A call to action: public health and community college partnerships to educate the workforce and promote health equity. J Public Health Manag Prac. 2008;14:S82-4.

25. Association of Schools of Public Health. ASPH policy brief - Creating a culture of wellness: building health care reform on prevention and public health. Washington, DC: The Association; 2010. Available from URL: http://www. asph.org/UserFiles/Prevention-and-Public-Health-Strategies-for-HCReform-asph-policy-paper2009.pdf (Accessed 5 January, 2011).

26. Maciosek MC, Coffield AB, Flottemesch TJ, Edwards NM, Solberg LI. Greater use of preventive services in the US health care could save lives at little or no cost. Health Aff (Millwood). 2010;29:1656-60. 
27. McGinnis JM, Foege WH. The immediate vs. the important. JAMA. 2004; 291:1263-4.

28. Colgrove J, Fried LP, Northridge, ME, Rosner D. Schools of public health: essential infrastructure of a responsible society and a 21 st-century health system. Public Health Rep. 2010;125:8-14.

29. CDC Prevention Research Center (PRC) Program. Atlanta, GA: The Centers for Disease Control and Prevention; 2010. Available from URL: http://www.cdc. gov/prc/index.htm (Accessed 5 January, 2011).

30. Gebbie KM, Turnock BJ. The public health workforce 2006: New challenges. Health Aff (Millwood). 2006; 25:923-33.

31. Rahn DA, Wartman SA. For the health-care workforce, a critical prognosis. The Chronicle of Higher Education. 2 November, 2007.

32. Health Resources and Services Administration. Public health personnel in the United States 1980: second report to Congress. In: US Department of Health and Human Services, editor. Washington, DC: US Public Health Service; 1982.

33. National Center for Health Workforce Information and Analysis, Center for Health Policy at the Columbia University School of Nursing, Bureau of Health Professions. The public health workforce enumeration 2000. In: Health Resources and Services Administration (HRSA), editor. Washington, DC: Health Resources and Services Administration; 2000.

34. US Census Bureau 2008. Washington, DC: US Census Bureau; 2010 [updated 14 December, 2010]. Available from URL: http://www.census.gov/ compendia/statab/past_years.html;http://www.census.gov/acs/www/data_ documentation/2008_release/ (Accessed 5 January, 2011).

35. Perlino CM. Issue brief - the public health workforce shortage: left unchecked, will we be protected? Washington DC: American Public Health Association (APHA); 2006. Available from URL: http://www.apha.org/NR/rdonlyres/ 8B9EBDF5-8BE8-482D-A779-7F637456A7C3/0/workforcebrief.pdf (Accessed 5 January 2011).

36. Trust for America's Health. Public health workforce shortages. Washington, DC. Available from URL: http://healthyamericans.org/assets/files/PHWorkforce. pdf (Accessed 5 January, 2011).

37. Association of Academic Health Centers (AAHC). Out of order, out of time: the state of the nation's public health workforce: a report by the Association of Academic Health Centers. Washington, DC: Association of Academic Health Centers; 2008. Available from URL: http://www.aahcdc.org/policy/AAHC_ OutofTime_4WEB.pdf (Accessed 24 June, 2011).

38. American Association of Medical Colleges (AAMC). Physician shortages to worsen without increases in residency training. Available from URL: https:// www.aamc.org/newsroom/newsreleases/2010/150570/100930.html (Accessed 5 January, 2011).

39. Sullivan Commission on Diversity in the Healthcare Workforce. Missing Persons: minorities in the health professions. Washington, DC; 2004. 
40. World Health Organization (WHO). Taking stock: health worker shortages and the response to AIDS. 2006. Available from URL: http://www.who.int/hiv/ toronto2006/TTR2_eng.pdf (Accessed 24 June, 2011).

41. World Health Organization (WHO). Working together for health: world health report 2006. Geneva, Switzerland; 2006.

42. Fried LP, Bentley ME, Buekens P, Burke DS, Frenk JJ, Klag MJ, et al. Global health is public health. Lancet. 2010; 375:535-7.

43. Koplan JP, Bond TC, Merson MH, et al. Towards a common definition of global health. Lancet. 2009;373:1993-5.

44. Korstad RR. Dreaming of a time: the School of Public Health: the University of North Carolina at Chapel Hill, 1939-1989. Chapel Hill: The University of North Carolina at Chapel Hill; 1990.

45. Henderson DA. On the eradication of smallpox and the beginning of a public health career. Public Health Reviews. 2011;33:19-29.

46. Hagopian A, Spigner C, Gorstein JL, Mercer MA, Pfeiffer J, Frey S, et al. Developing competencies for a graduate school curriculum in international health. Public Health Rep. 2008;123:408-14.

47. CDC Task Force on Community Preventive Services. The Community Guide. Atlanta, GA: The Community Guide Branch; 2010. Available from URL: http://www.thecommunityguide.org/index.html. (Accessed 5 January, 2011).

48. 2009-2010 (111th Congress). Patient Protection and Affordable Care Act.

Washington, DC: US Congress, 2010. Available from URL: http://www. govtrack.us/congress/billtext.xpd?bill=h111-3590. (Accessed 5 January, 2011).

49. Institute of Medicine of the National Academies (IOM). Committee on Comparative Effectiveness Research Prioritization Board on Health Care Services. Initial national priorities for comparative effectiveness research. Washington, DC: National Academies Press; 2009.

50. Davidson C, Goldberg DT. The future of learning institutions in the digital age. Cambridge: MIT Press; 2009.

51. Prensky M. Teaching digital natives. Thousand Oaks: Corwin Press; 2010. 